\title{
Effect of asthma and its treatment on growth: four year follow up of cohort of children from general practices in Tayside, Scotland
}

\author{
C McCowan, R G Neville, G E Thomas, I K Crombie, R A Clark, I W Ricketts, A Y Cairns, \\ F C Warner, S A Greene, E White
}

Tayside Centre for
General Practice,
University of
Dundee, Dundee
DD2 4AD
C McCowan,
project officer,
National Asthma
Campaign
R G Neville,
senior lecturer in
general practice
G E Thomas,
lecturer in statistics
I K Crombie,
reader in
epidemiology
R A Clark,
consultant chest
physician
I W Ricketts,
reader in computer
studies
A Y Cairns,
lecturer in computer
studies
F C Warner,
research secretary in
general practice
S A Greene,
consultant paediatric
endocrinologist
E White,
health visitor
Correspondence to:
Mr McCowan
c.mccowan@
dundee.ac.uk

BMJ 1998;316:668-72

\begin{abstract}
Objective: To investigate whether asthma or its treatment impairs children's growth, after allowing for socioeconomic group.

Design: 4 year follow up of a cohort of children aged $1-15$.

Setting: 12 general practices in the Tayside region of Scotland.

Subjects: 3347 children with asthma or features suggestive of asthma registered with the general practices.

Main outcome measures: Height and weight standard deviation scores.

Results: Children who lived in areas of social deprivation (assessed by postcode) had lower height and weight than their contemporaries (mean standard deviation score -0.26 (SD 1.02) and -0.18 (1.15) respectively, $\mathrm{P}<0.001$ for both). Children who were receiving $\geqslant 400 \mu \mathrm{g}$ daily of inhaled steroids and who were attending both hospital and general practice for asthma care had lower height and weight than average, independent of the effect of deprivation (mean standard deviation score -0.62 (1.01), $\mathrm{P}=0.002$, for height and -0.58 (0.94), $\mathrm{P}=0.005$, for weight). Children receiving high doses of inhaled corticosteroids also showed lower growth rates (mean change in standard deviation score - 0.19 (0.51), $\mathrm{P}=0.003)$. However, no other children with asthma showed growth impairment.

Conclusion: Most children with asthma were of normal height and weight and had normal growth rates. However, children receiving high doses of inhaled steroids and requiring both general practice and hospital services had a significant reduction in their stature. This effect was independent from but smaller than the effect of socioeconomic group on stature.
\end{abstract}

\section{Introduction}

Some studies have shown that children with asthma have impaired growth, ${ }^{1-4}$ some have shown this change to be merely a transient phase brought on by a delay in the onset of puberty, ${ }^{56}$ and others have found no relation. $^{7-9}$ The concerns of parents and health profes- sionals about the safety of asthma treatment are difficult to allay without modern large studies on the topic.

The use of potent inhaled corticosteroids to control asthma has led to speculation about the specific effect they have on growth, with opinion once again divided. Littlewood et al, ${ }^{1}$ among others, ${ }^{3}{ }^{4}$ have reported that children receiving high doses of inhaled corticosteroids are shorter than average. Wolthers and Pedersen found no effect on growth of low doses of inhaled corticosteroids in children attending their asthma clinic who were followed up over 4 years. ${ }^{4}$

The measurement of growth in children has itself been an area of intense study, with new growth references for the United Kingdom being produced and new methods for measuring growth being championed. ${ }^{10-12}$ The Tanner growth standards developed in the 1960s and commonly used throughout the United Kingdom ${ }^{13}$ were shown to be out of date as the average height of British children had increased over time. ${ }^{14} 15$ The method of comparing the growth in children also changed, with a standard deviation score being preferred to the growth centile. New methods of calculating growth have led to the development of new growth charts. $^{12}$

Several growth studies in general populations have investigated the effect of socioeconomic group on growth and have shown that children from more socially deprived backgrounds tend to be shorter. ${ }^{16-18}$ Results from the Tayside growth study support this and also suggest that children from Tayside are in general shorter than the average height for children in the United Kingdom. Studies examining links between socioeconomic group and asthma have been evenly divided about an effect. ${ }^{19}$

Previous studies on growth and asthma have been hospital based, looking at children with severe asthma referred from the local community. Many of these did not allow for socioeconomic influences on growth or use modern population based methods for comparing growth.

The cohort of children in the Tayside childhood asthma project had asthma of varying severity and was drawn from primary care in one region. Previous work in this cohort found that children receiving high doses 
of inhaled steroids were shorter than expected..$^{20}$ The opportunity thus arose to study height and weight over time and so investigate the relation between growth, asthma, its treatment, and other factors such as deprivation and use of health services.

\section{Subjects and methods}

\section{Subjects}

Two independent long term studies formed the basis for this study. The Tayside growth study accurately measured the height and weight of children in the region every two years from 1989 to 1995 , while the Tayside childhood asthma project independently tracked the management of an identified group of children with asthma or features suggestive of asthma from 1990 to $1995 .^{2122}$

The children in the Tayside childhood asthma project were traced through the growth study and their growth records combined with their medical records to form a single database. Some growth measurements retrieved were outside the scope of the childhood asthma project because the growth study ran for slightly longer than the asthma project, the asthma project had a broader age band, and some children changed general practice during the course of the studies. When children changed general practice they would no longer participate in the child asthma project but could still be measured in the growth study.

Heights and weights of individual children were converted to standard deviation scores for boys and girls separately using the LMS method. ${ }^{12}$ The reference population used to calculate the scores was all Tayside children $(>20000)$ in the year the measurement was obtained. ${ }^{18}$ When a child had two or more height measurements separated by at least six months the change in height standard deviation score between consecutive measurements was used to monitor growth rate..$^{23}$

Each child's asthma treatment was classed according to the British Thoracic Society's treatment steps $0-4 .{ }^{24}$ The highest treatment step was used for children who were prescribed different treatments within the same year.

Each child was also grouped according to his or her annual use of health services to give an indicator of the severity of asthma. The children were grouped into three categories: those who had received no attention for asthma, those who received attention solely from their general practice, and those who received attention at both hospital and their general practice.

Home postcodes for all children were recorded, and these were used to assign an index of deprivation based on the 1991 census. ${ }^{25}$ The children were then grouped into quarters according to the value of their index of deprivation. This gave a group of high socioeconomic status, two moderate groups, and one group with low socioeconomic status, which contained children who were socially deprived. The index of deprivation used was determined according to the prevalence of several different factors within each postcode: unemployment, overcrowding, lack of amenities, children in unsuitable accommodation or in low earner households, no car, and single parent families. The index had a range of values in which the national average was zero, better than average scores were negative, and worse than average scores were positive.

\section{Statistical methods}

The main measurements analysed were height and weight standard deviation score. Mean scores in subgroups defined by treatment step and use of health services were compared with the reference population of the Tayside growth study ${ }^{21}$ and with each other. Various statistical methods were used to interpret differences between group mean scores.

In a large population the distribution of standard deviation scores is normal and so any subgroup drawn at random from the population should also have a mean score of 0 with a standard deviation equal to 1 , apart from variation due to sampling. If the mean of a sample of size $n$ is outside the limits of $\pm 2 / n$ there is evidence of a difference from the reference population. Again, in a large population change in height standard deviation scores between two given ages should be normally distributed, with a mean of 0 and a standard deviation equal to $(2(1-r))$, where $r$ is the correlation between standard deviation scores at the two ages. ${ }^{23}$ An average value for $r$ over the age range in the study was between 0.85 and 0.9 , giving a standard deviation for mean change in height standard deviation score of between 0.55 and 0.45 .

For all variables the one way analysis of variance was used to compare subgroups of children. After the effects of confounding covariates were allowed for, pairwise subgroups of interest were compared using Scheffe's post hoc test. For two subgroups this approach is equivalent to Student's $t$ test. When the grouping of children was ordered, a possible trend across the groups was investigated using a simple linear trend term with its associated $\mathrm{F}$ test.

\section{Ethics}

The project was approved by the Tayside Medical Ethics Committee, and all computer data were stored under the terms of the Data Protection Act.

\section{Results}

\section{The cohort}

A cohort of 3437 children were identified from their medical records as having asthma or asthma related features. ${ }^{22}{ }^{26}$ Twenty six children were removed from the study because they had systemic diseases that could impair their growth-for example, cystic fibrosis, congenital heart disease, or Down's syndrome. Height measurements were traced for $2853(84 \%)$ of the remaining children. The 558 children without a traceable measurement showed a similar breakdown by treatment step and use of health services to that in the children who had a measurement, but the proportion of girls was higher (table 1). In addition, 498 children who had no related asthma record for the year a growth measurement was taken were discounted from any further analysis.

This left 2355 children (69\% of the population of the Tayside childhood asthma project) who had at least one height measurement recorded in a year when their asthma treatment was documented. There was a slight preponderance of boys (1355/2355 (58\%)), and the average age of children at the time of the last growth measurement was 9.7 years. The distribution of standard deviation scores for the height and weight of this cohort showed no obvious differences from the 
Table 1 Characteristics of children with and without growth measurement. Values are numbers (percentages) of children

\begin{tabular}{lcc} 
& $\begin{array}{c}\text { Without growth } \\
\text { measurement } \\
(\mathbf{n = 5 5 8 )}\end{array}$ & $\begin{array}{c}\text { With growth } \\
\text { measurement } \\
\mathbf{( n = 2 8 5 3 )}\end{array}$ \\
\hline Sex: & $290(52)$ & $1648(58)$ \\
\hline Male & $268(48)$ & $1205(42)$ \\
\hline Female & \\
\hline BTS treatment step ${ }^{24}$ : & $1924(67)$ \\
\hline 0 & $362(65)$ & $435(15)$ \\
\hline 1 & $101(18)$ & $61(2)$ \\
\hline 2 & $10(2)$ & $174(6)$ \\
\hline 3 & $36(6)$ & $259(9)$ \\
\hline 4 & $49(9)$ & $1594(56)$ \\
\hline Use of health services: & $1124(39)$ \\
\hline No contact & $304(54)$ & $135(5)$ \\
\hline GP only & $227(41)$ \\
\hline GP and hospital services & $27(5)$ &
\end{tabular}

normal distribution for the Tayside population. ${ }^{21}$ In all, 1405 children had height measurements taken on two or more occasions at least six months apart (table 2).

\section{Deprivation}

Table 2 shows the means and standard deviations for height and weight standard deviation scores when the children were grouped by the index of deprivation. The affluent groups were taller and heavier on average than the reference population, while the most deprived children were shorter and lighter on average. Overall, children were on average shorter and lighter with increasing deprivation. There was very strong evidence of differences between the deprivation groups for both height and weight standard deviation score $(\mathrm{P}<0.001$ for both). For both variables most of the variation could be accounted for by a simple linear trend with degree of deprivation.

\section{Treatment step}

When the children were classed by treatment steps, ${ }^{24}$ only the group of children receiving step 4 treatment (high doses of inhaled steroids) was found to be shorter on average than the reference population, although there was no strong evidence that the group was lighter on average (table 2).

When the effect of deprivation on height standard deviation score was allowed for, the children at treatment step 4 were significantly shorter than the others $(\mathrm{P}=0.02)$. For weight there were no differences between treatment groups $(\mathrm{P}=0.2)$. However, mean weight standard deviation score declined with treatment step by 0.047 (SE 0.019) per step $(\mathrm{P}=0.02)$.

\section{Use of health services}

The children who had received medical care from both their general practitioner and hospital services were shorter and lighter on average than expected, whereas the other two groups showed no differences from the reference population (table 2 ). ${ }^{21}$

For height there was no evidence of differences between the three groups after allowing for the effects of deprivation $(\mathrm{P}=0.16)$, but for weight there was evidence of differences $(\mathrm{P}=0.002)$, the group receiving care from both their general practice and hospital being lighter on average than the other groups.

The children were classed by treatment step (step 4 $v$ the rest) and use of health services (general practitioner and hospital $v$ the rest) (table 3). The children receiving step 4 treatment and care from both hospital and general practitioner were shorter and lighter than expected. Even after allowance was made for degree of deprivation, these children were on average shorter $(\mathrm{P}=0.002)$ and lighter $(\mathrm{P}=0.003)$ than the other children. On average, height and weight of children in the three other groups showed no differences from the reference population or from each other.

\section{Growth rates}

There were no differences in growth rates for any of the deprivation groups when compared with the expected average growth rate of the reference population (table 2). There was also no evidence of a trend throughout these four groups as deprivation increased $(\mathrm{P}=0.13)$.

Table 2 Height and weight distribution of children with growth record and associated asthma record

\begin{tabular}{|c|c|c|c|c|c|c|}
\hline \multirow[b]{2}{*}{ Population } & \multicolumn{2}{|c|}{ Height } & \multicolumn{2}{|c|}{ Weight } & \multicolumn{2}{|c|}{ Change in height SDS } \\
\hline & $\begin{array}{c}\text { No of } \\
\text { children }\end{array}$ & Mean (SD) & $\begin{array}{c}\text { No of } \\
\text { children }\end{array}$ & Mean (SD) & $\begin{array}{c}\text { No of } \\
\text { children }\end{array}$ & Mean (SD) \\
\hline All & 2355 & $-0.02(1.02)$ & 2135 & $0.03(1.07)$ & 1405 & $0.00(0.54)$ \\
\hline \multicolumn{7}{|l|}{ Social status: } \\
\hline Very affluent & 545 & $0.16(1.01)^{*}$ & 480 & $0.15(0.99)^{*}$ & 333 & $0.02(0.55)$ \\
\hline Affluent & 546 & $0.09(0.99)^{*}$ & 463 & $0.16(1.15)^{\star}$ & 324 & $0.04(0.50)$ \\
\hline Deprived & 554 & $-0.07(1.01)$ & 517 & $0.02(0.98)$ & 363 & $-0.02(0.53)$ \\
\hline Very deprived & 552 & $-0.26(1.02)^{*}$ & 520 & $-0.18(1.15)^{\star}$ & 385 & $-0.02(0.57)$ \\
\hline Unknown & 158 & $-0.06(1.04)$ & 155 & $0.03(1.06)$ & & \\
\hline \multicolumn{7}{|l|}{ BTS treatment step ${ }^{24}$ : } \\
\hline 0 & 1405 & $-0.01(1.03)$ & 1287 & $0.05(1.09)$ & 894 & $0.01(0.56)$ \\
\hline 1 & 573 & $0.02(1.00)$ & 508 & $0.06(1.00)$ & 284 & $0.03(0.50)$ \\
\hline 2 & 82 & $0.00(1.00)$ & 65 & $-0.03(1.09)$ & 38 & $0.11(0.49)$ \\
\hline 3 & 126 & $-0.02(1.00)$ & 121 & $-0.15(1.02)$ & 80 & $-0.00(0.47)$ \\
\hline 4 & 169 & $-0.28(1.05)^{\star}$ & 154 & $-0.12(1.22)$ & 109 & $-0.19(0.51)^{\star}$ \\
\hline \multicolumn{7}{|l|}{ Use of health services: } \\
\hline No contact & 1065 & $-0.03(1.03)$ & 979 & $0.04(1.11)$ & 691 & $0.01(0.58)$ \\
\hline GP only & 1171 & $0.01(1.00)$ & 1047 & $0.05(1.04)$ & 654 & $0.00(0.50)$ \\
\hline GP and hospital services & 119 & $-0.32(1.13)^{\star}$ & 109 & $-0.32(1.02)^{\star}$ & 60 & $-0.07(0.49)$ \\
\hline
\end{tabular}

SDS=standard deviation score; BTS=British Thoracic Society; GP=general practitioner.

${ }^{*}$ Significantly different from reference population of Tayside growth study. ${ }^{21}$ 
Table 3 Height and weight in children classed by British Thoracic Society treatment step ${ }^{24}$ and use of hospital services

\begin{tabular}{|c|c|c|c|c|c|c|}
\hline \multirow[b]{2}{*}{ Population } & \multicolumn{2}{|c|}{ Height } & \multicolumn{2}{|c|}{ Weight } & \multicolumn{2}{|c|}{ Change in height SDS } \\
\hline & $\begin{array}{c}\text { No of } \\
\text { children }\end{array}$ & Mean (SD) & $\begin{array}{c}\text { No of } \\
\text { children }\end{array}$ & Mean (SD) & $\begin{array}{c}\text { No of } \\
\text { children }\end{array}$ & Mean (SD) \\
\hline \multicolumn{7}{|l|}{ Treatment steps $0-3$} \\
\hline No contact and GP only & 2130 & $-0.01(1.01)$ & 1932 & $0.04(1.06)$ & 1276 & $0.02(0.54)$ \\
\hline GP and hospital & 56 & $0.02(1.18)$ & 49 & $-0.01(1.04)$ & 20 & $0.16(0.47)$ \\
\hline No contact and GP only & 106 & $-0.07(1.03)$ & 94 & $0.17(1.29)$ & 69 & $-0.19(0.54)^{*}$ \\
\hline GP and hospital & 63 & $-0.62(1.01)^{\star}$ & 60 & $-0.58(0.94)^{\star}$ & 40 & $-0.18(0.46)^{\star}$ \\
\hline
\end{tabular}

$\mathrm{SDS}=$ standard deviation score; GP=general practitioner.

${ }^{\star}$ Significantly different from reference population of Tayside growth study. ${ }^{21}$

When classed by treatment step, only the children on step 4 showed a lower growth rate than the reference population (table 2). ${ }^{21}$ Also, this group had a significantly lower growth rate than the others $(\mathrm{P}=0.003)$.

The average growth rates of the children classed by use of health services showed no differences from the reference population or between the three groups $(\mathrm{P}=0.27)$. A comparison of children given step 4 treatment who were attending hospital and their general practitioner for asthma management with those on step 4 who were not showed no differences between the two groups, although the growth rate was lower in both groups than for the reference population (table 3 ). ${ }^{21}$

\section{Discussion}

The results from this study show that most children being treated for asthma do not have growth impairment. A small subset of children were significantly shorter and lighter, and this was principally associated with low socioeconomic group but with some association with asthma.

Children in this study receiving step 4 treatment in the British Thoracic Society's guidelines (high doses of inhaled corticosteroids ${ }^{24}$ who use hospital services are shorter and lighter than expected and also have comparatively poor growth rates. Those on step 4 who did not use hospital services were of normal height and weight but also showed comparatively poor growth rates. The reduction in stature due to asthma is not simply a result of treatment but arises from a complex interplay of factors, possibly including degree of control and the underlying severity of asthma. At present we are unable to quantify any such effects.

Socially deprived children as determined by postcode were significantly shorter and lighter than the reference population. The children from more affluent backgrounds were significantly taller and heavier than the reference population. These results agree with those reported by other growth studies. ${ }^{16-18}$ By contrast there were no differences in average growth rates across the socioeconomic scale.

Severity of asthma, whether classed by treatment or use of health care facilities, was not strongly associated with socioeconomic group. There was a trend for children with severe asthma, by intensity of treatment or care, to be poorer, but it was not significant.

\section{Problems with methods}

There are many difficulties with large scale population studies such as this. The Tayside growth study was designed to monitor the change in growth of the population, not individual children, and so pubertal stage was not recorded when measurements were taken. Thus the study is not able to determine whether asthma or its treatment have an effect on puberty or indicate what effect might be present. As asthma was generally assessed only once for each child, we could not assess the effects on growth of the duration of asthma or its treatment.

Data collection in the Tayside childhood asthma project was restricted to general purpose general practitioner medical records, so it was difficult to obtain an objective assessment of the severity of asthma that was independent of the treatment. As a compromise, children were classed by use of health services, which was considered to be a proxy for the impact of asthma on children.

Using a large, current, and local population allows easy comparison of different growth measurements by standard deviation score. The method devised by Cole and Green allows the standard deviation score of children of different age and sex to be compared, so populations of children can be studied. ${ }^{12}$ The population was drawn from 12 different Tayside general practices, so gave it a representative sample of the region. The 12 general practices had been selected to give a mix of urban and rural areas, single handed and multipartner practices, and practices with and without an asthma clinic. ${ }^{22}$ Any strong socioeconomic bias from drawing subjects from a single centre was avoided, and the group included the full range of asthma, which is not found in specialist hospital asthma clinics.

\section{Deprivation}

An index of deprivation based on postcode allows the effect of socioeconomic group on asthma and growth to be assessed. That our marker was based on a validated index of deprivation, ${ }^{25}$ only the single parent family factor being different, should allay fears that a biased marker was used. The findings confirm that growth is related to socioeconomic group. ${ }^{16-18}$ The suggestion of a trend for people from poorer socioeconomic groups to have more severe asthma agrees with some recent publications, although previous work is divided about the effect of social group on asthma. ${ }^{19}$ We could not obtain specific data on deprivation for the Tayside population as the home postcodes for individual children were not recorded. Within the confines of this study we were not able to determine whether the prevalence of asthma was affected by the degree of deprivation. 
sible for the design of the Tayside growth study, the running of the project, and writing the paper. EW contributed to the design of the project, particularly the Tayside growth study, ran the growth study, and contributed to the paper. RGN and SAG are guarantors for the study.

Funding: Growth and asthma in Tayside children and the childhood asthma project were sponsored by grants from the National Asthma Campaign. The Tayside growth study was sponsored by grants from Kabi Pharmacia and Clinical Resource and Audit Group, Scottish Office.

Conflict of interest: None.

- Children who received high doses of inhaled corticosteroids and used hospital services for asthma were shorter and lighter than their contemporaries after social deprivation was allowed for

- Children receiving high doses of inhaled corticosteroids had lower than normal growth rates

\section{Conclusion}

Our findings could help explain why there has been such a diversity in the results from previous work. ${ }^{27}$ Community based studies have shown that asthma has no effect on growth, while hospital studies concentrating on small numbers of severely asthmatic children receiving high doses of inhaled steroids have reported impaired growth. Our study suggests that only a small subset of children have impaired stature-those who require hospital management and are prescribed high doses of inhaled steroids-and this would explain the findings of previous reports. If these children are included as part of a larger community based study the impairment to their stature is masked by children whose stature is not affected. The results also imply that high doses of inhaled corticosteroids may affect growth rate. Whereas the paper cannot answer the debate on severity and treatment, high doses of inhaled steroids seem not to affect stature, although they may adversely effect growth rate. Reduction in stature is thus caused by a combination of influences, including degree of control and severity of asthma.

We thank all the general practice staff and school nurses who made the Tayside growth study and the childhood asthma project possible. We also thank Dr George Russell (University of Aberdeen) and Dr Tim Cole (Medical Research Council Dunn Nutrition Unit, Cambridge) for their constructive criticism of this paper, and Mr W Berry (University of Dundee) for his work with the deprivation index.

Contributors: CMcC supervised data collection, analysed data, and wrote the paper. RGN was responsible for the design of the study, particularly the childhood asthma project, and contributed to the running of the project and writing the paper. GET was responsible for the statistical analysis of the data and contributed to the design and running of the project and to writing the paper. IKC and RAC contributed to the design of the project, particularly to the childhood asthma project, to running the project, and to writing the paper. IWR contributed to the design and running of the project and to writing the paper. AYC contributed to the design of the project, particularly the Tayside growth study, to running the project, and to writing the paper. FCW was responsible for data collection and contributed to running the project and to writing the paper. SAG was respon-
1 Littlewood JM, Johnson AW, Edwards PA, Littlewood AE. Growth retardation in asthmatic children treated with inhaled beclomethasone dipropionate. Lancet 1988;i:115-6.

2 Murray AB, Fraser B, Hardwick DF, Pirie G. Chronic asthma and growth failure in children. Lancet 1976;ii:197-8.

3 Wales J, Barnes N, Swift P. Growth retardation in children on steroids for asthma. Lancet 1991;338:1535.

4 Wolthers OD, Pedersen S. Growth of asthmatic children during treatment with budesonide: a double blind trial. BMJ 1991;303:163-5.

5 Balfour-Lynn L. Growth and childhood asthma. Arch Dis Child 1986;61:1049-55

6 Hauspie RC, Gyenis G, Alexander F, Simon G, Susanne C, Madach A Heights and weights of Hungarian and Belgian asthmatic boys. Hum Biol 1979;51:507-21.

7 Agertoft L, Pedersen S. Effects of long term treatment with an inhaled corticosteroid on growth and pulmonary function in asthmatic children. Respir Med 1994;88:373-81.

8 Ninan TK, Russell G. Asthma, inhaled corticosteroid treatment, and growth. Arch Dis Child 1992;67:703-5.

9 Power C, Manor O. Asthma, enuresis, and chronic illness: long term impact on height. Arch Dis Child 1995;73:298-304.

10 Hall DMB. Monitoring children's growth. BMJ 1995;311:583-4

11 Cole TJ. Do growth chart centiles need a facelift? BMJ 1994;308:641-2.

12 Cole TJ, Green PJ. Smoothing reference centile curves: the LMS method and penalised likelihood. Stat Med 1992;11:1305-19.

13 Tanner JM, Whitehouse RH, Takaishi M. Standards from birth to maturity for height, weight, height velocity, and weight velocity: British children, 1965. Part I. Arch Dis Child 1966:41:454-71.

14 Voss L, Walker J, Lunt H, Wilkin T, Betts P. The Wessex growth study: first report. Acta Paediatr Scand 1989;349(suppl):65-72.

15 Smith A, Chinn S, Rona R. Social factors and height gain of primary schoolchildren in England and Scotland. Ann Hum Biol 1980;7:115-24.

16 Rona J, Swan AV, Altman DG. Social factors and height of primary school children in England and Scotland. I Epidemiol Community Health 1978:32:147-54.

17 Gulliford M, Chinn S, Rona R. Social environment and height : England and Scotland 1987 and 1988. Arch Dis Child 1991;66:235-40.

18 White E, Wilson A, Greene SA, Berry W, McCowan C, Cairns AY, Ricketts IW. Growth screening and urban deprivation. J Med Screening $1995 ; 2: 140-5$.

19 Mielck A, Reitmeir P, Wjst M. Severity of childhood asthma by socio-economic status. Int J Epidemiol 1996;25:388-93.

20 Neville RG, McCowan C, Thomas G, Crombie I K. Asthma and growthcause for concern? Ann Hum Biol 1996;23:323-31.

21 White EM, Wilson AC, Greene SA, McCowan C, Thomas GE, Cairns AY, et al. Body mass index centile charts to assess fatness of British children. Arch Dis Child 1995; $72 \cdot 38-41$.

22 Bryce FP, Neville RG, Crombie IK, Clark RA, McKenzie P. Controlled tria of an audit facilitator in diagnosis and treatment of childhood asthma in general practice. $B M J 1995 ; 310: 838-42$.

23 Cole TJ. Growth monitoring with the British 1990 growth reference. Arch Dis Child 1997;76:47-9.

24 British Thoracic Society Guidelines on the management of asthma. Thorax 1993;48:S1-24.

25 Department of Environment. 1991 Deprivation index, a review of approaches and a matrix of results. London: HMSO, 1995.

26 Neville RG, Bryce FP, Robertson FM, Crombie IK, Clark RA. Diagnosis and treatment of asthma in children: usefulness of a review of medical records. Br J Gen Pract 1992:42:501-3.

27 Russell G. Childhood asthma and growth-a review of the literature Respir Med 1994;88(suppl):A31-7.

(Accepted 28 October 1997)

\section{One hundred years ago Special correspondence: Berlin}

The Berlin vegetarians have a fine new feather in their caps. In a walking match of 15 German miles, about 70 English miles, all the 6 vegetarians who started passed the goal in perfect condition, showing no trace of excessive fatigue, whilst of 11 non-vegetarians only one was able to hold out to the end, and he arrived long after the others and very weary. The vegetarian victor did the distance - comfortably from his account-in fourteen hours and a quarter. He was sent for next day by the medical department of the Prussian War Ministry, and interrogated as to his training, diet, etc. (BMJ 1898;ii:116) 